\title{
Static Voltage Stability Assessment of the Kenyan Power Network
}

\author{
Ombuki Mogaka $(\mathbb{D}$, Roy Orenge $(\mathbb{D}$, and Julius Ndirangu $(\mathbb{D})$ \\ Department of Electrical and Electronic Engineering, Jomo Kenyatta University of Agriculture and Technology (JKUAT), \\ Nairobi 62000-00200, Kenya \\ Correspondence should be addressed to Ombuki Mogaka; ombukibrighton@gmail.com, Roy Orenge; roy.orenge@jkuat.ac.ke, \\ and Julius Ndirangu; julzndirangu@gmail.com
}

Received 27 July 2020; Revised 13 October 2020; Accepted 8 February 2021; Published 24 February 2021

Academic Editor: Daniela Proto

Copyright (c) 2021 Ombuki Mogaka et al. This is an open access article distributed under the Creative Commons Attribution License, which permits unrestricted use, distribution, and reproduction in any medium, provided the original work is properly cited.

\begin{abstract}
In recent years, the Kenyan Power Network has witnessed large growths in load demand. Although the increased load demand has somewhat been matched with an increase in transmission and generation capacity, the rate of expansion has not been matched with the rate of increase in load demand due to economic, environmental, and geographical constraints. This has led to the system being prone to instability since it is being operated under stressed conditions. In the recent past, several studies have been carried out on voltage stability analysis and improvement using various conventional methods. However, conventional methods have various limitations in their utilization for voltage stability analysis. One solution to overcome these limitations is to employ a combination of one or more methods so as to get more information and greater degree of accuracy in voltage stability studies. In this paper, a methodology is proposed involving the combination of QV modal analysis, sensitivity analysis (VQ) and powervoltage curves in assessing the static voltage stability analysis taking a case study of the Kenyan Power Network. V-Q sensitivity analysis and QV modal analysis have been used to identify the load regions most susceptible to voltage instability and the corresponding weak buses in the network for various V-Q responses. Reactive power loss sensitivities for branches in the network have been used to determine the critical (weak) lines in the network. Loading margins (LM) and voltage stability margins (VSM) have then been used to determine the proximity to voltage collapse of the voltage weak buses identified by QV modal analysis. The effect of tripping one the critical lines on the voltage weak buses is also investigated. The current high voltage power network under the average peak loading conditions during the year 2019 is considered for the study. The paper also reviews existing voltage stability analysis methods and their limitations.
\end{abstract}

\section{Introduction}

Due to economic and environmental constraints, bulk power systems are increasingly being operated close to their limits which have made them more prone to instability and power quality challenges. Voltage instability is one of the problems that has gained notoriety in recent years. It has been recognized as one of the major sources of power system insecurity and has been responsible for several partial or full power interruptions over the past decades. In fact, more than 50 cases of voltage collapse have been reported around the world in the past 50 years. Notable incidents of interruptions that arose from voltage instability include the ones of France
(1978), Belgium (Aug 1982), Sweden (Dec 1983), Tokyo, Japan (July 1987), USA Tennessee (Aug 1987), Canada (March 1989), and the USA's WSCC power grid blackouts (July 2 and Aug. 10 1996). These incidents led to power interruptions to millions of consumers in some of the countries and losses in the range of millions. Some of the incidents reported over the years are presented in Table 1 together with the time frames and total load interruptions reported [2-10].

Several definitions of voltage stability and related terms are provided in the literature [11-15]. In general, voltage stability is associated with the ability of a power system to maintain acceptable voltages at all the buses in a power system under normal operations conditions and after being 
TABLE 1: Reported voltage collapse incidents over the years [1].

\begin{tabular}{|c|c|c|c|c|}
\hline Date $(\mathrm{mm} / \mathrm{dd} / \mathrm{yy})$ & Location & $\begin{array}{l}\text { Time } \\
\text { frame }\end{array}$ & $\begin{array}{l}\text { Interrupted } \\
\text { load }\end{array}$ & Remarks \\
\hline $08 / 22 / 70$ & Japan & $\begin{array}{l}30 \\
\text { minutes }\end{array}$ & - & - \\
\hline $07 / 23 / 78$ & Japan (Tokyo) & $\begin{array}{l}20 \\
\text { minutes }\end{array}$ & $8.168 \mathrm{GW}$ & - \\
\hline $12 / 19 / 78$ & France & $\begin{array}{l}26 \\
\text { minutes }\end{array}$ & $29 \mathrm{GW}$ & $\begin{array}{l}\text { Estimated cost: } \\
\$ 200-300 \text { million }\end{array}$ \\
\hline $08 / 04 / 82$ & Belgium & $\begin{array}{l}4.5 \\
\text { minutes }\end{array}$ & - & - \\
\hline $\begin{array}{l}09 / 02 / 82,11 / 26 / \\
82,30 / 11 / 82\end{array}$ & USA (Florida) & $\begin{array}{l}1-3 \\
\text { minutes }\end{array}$ & $2 \mathrm{GW}$ & - \\
\hline $12 / 27 / 82$ & Sweden & $\begin{array}{c}55 \\
\text { seconds }\end{array}$ & $11.4 \mathrm{GW}$ & - \\
\hline $05 / 17 / 85$ & $\begin{array}{l}\text { USA (South } \\
\text { Florida) }\end{array}$ & 4 seconds & $4.292 \mathrm{GW}$ & - \\
\hline $11 / 30 / 86$ & $\begin{array}{l}\text { S. E Brazil, } \\
\text { Paraguay }\end{array}$ & 2 seconds & $>1.2 \mathrm{GW}$ & - \\
\hline $01 / 12 / 87$ & Western France & $\begin{array}{l}\text { 6-7 } \\
\text { minutes }\end{array}$ & $\sim 9 \mathrm{GW}$ & $\begin{array}{l}\text { System did not collapse but stabilised at low voltage level; } 0.5-0.8 \mathrm{pu} \\
\text { and recovered after shedding } 1.5 \mathrm{GW}\end{array}$ \\
\hline $08 / 22 / 87$ & $\begin{array}{c}\text { USA } \\
\text { (W. Tennessee) }\end{array}$ & $\begin{array}{c}10 \\
\text { seconds }\end{array}$ & $1.265 \mathrm{GW}$ & - \\
\hline $06 / 08 / 85$ & Israel & $\begin{array}{c}19 \\
\text { minutes }\end{array}$ & $\sim 3.140 \mathrm{GW}$ & - \\
\hline May 1997 & Chile & $\begin{array}{l}30 \\
\text { minutes }\end{array}$ & $2 \mathrm{GW}$ & - \\
\hline $08 / 14 / 03$ & USA, Canada & $\begin{array}{c}39 \\
\text { minutes }\end{array}$ & $63 \mathrm{GW}$ & Estimated cost: $\$ 4-10$ billion people affected: 50 million \\
\hline $09 / 23 / 03$ & $\begin{array}{l}\text { South Sweden, } \\
\text { East Denmark }\end{array}$ & - & $6.55 \mathrm{GW}$ & People affected: 4 million \\
\hline $07 / 12 / 04$ & S. Greece & $\begin{array}{c}30 \\
\text { minutes }\end{array}$ & $5 \mathrm{GW}$ & - \\
\hline $11 / 11 / 09$ & Brazil, Paraguay & $\begin{array}{c}68 \\
\text { seconds }\end{array}$ & $24.436 \mathrm{GW}$ & - \\
\hline $07 / 30 / 12,07 / 31 / 12$ & India & - & - & People affected; 700 million \\
\hline
\end{tabular}

subjected to a disturbance. Voltage instability on the other hand refers to the inability of a system to maintain acceptable voltages in some or all buses in the system under normal operating conditions and after being subject to disturbances, i.e., low-probability single or multiple contingencies, which cause a gradual and uncontrollable decline in voltage. It can also result from a mismatch between generation and demand of reactive power, the case in which a power system fails to meet the reactive power requirements. If corrective measures are not initiated to check voltage instability, a significant decrease in system voltage occurs, due to heavy reactive power losses. Consequently, voltage collapse occurs. Voltage collapse is a process by which a sequence of events accompanying voltage instability leads to an unacceptably low voltage profile in a significant part of a system $[12,14]$. It is characterised by heavy reactive power flows, inadequate reactive power support, and heavily loaded systems and results in partial or total system blackouts.

In Kenya, the government has been on a drive to connect more consumers to the national grid. The electricity access rate in Kenya has been on a steady rise over the last six years from $27 \%$ in 2013 to $77 \%$ in 2019 . The number of connected customers had risen from 1.5 million in 2010 to 7 million as of 2019. This increase in demand has not been matched by similar completion of transmission line projects. Consequently, the system is being operated closer to its stability limit and is thus more prone to instability in case of disturbances. This has put the system controllers under more pressure as they have to operate the system within lower security margins and defensively operate the system during conditions of peak loads. Therefore, the voltage instability problem leads to degradation in a power systems' performance and jeopardises the utility company's objective of delivering uninterruptible and reliable power supply to its customers. In order to avoid such occurrences, it is important that voltage stability analysis of the power system be undertaken.

Voltage stability analysis can be divided into dynamic and static voltage stability analyses. Both methods involve the examination of how far a system is to voltage instability and the mechanism of voltage instability, i.e., how and why voltage instability arises, the key factors contributing to instability, identification of voltage weak areas the network under study, and identifying the most effective measures of counteracting instability and by extension improving voltage stability $[15,16]$. 
Dynamic voltage stability analysis is based differential equations and deals with how bus voltages vary with changes in system operating parameters. It is useful in studying voltage collapse scenarios and understanding the chronology of events that lead to voltage collapse. Dynamic voltage stability methods include small signal stability analysis, time domain simulations, bifurcation analysis, and energy function method [16-22]. The features of the popular dynamic voltage stability methods are summarized in Table 2.

It is however noted that although voltage stability is a dynamic problem, much of the problem can be solved through static analysis since it yields most of the required information with regards to the voltage stability status of a system. Static analysis also takes less computational time and effort when compared to dynamic analysis and hence easier to carry out. Static voltage stability analysis involves computation of power flower equations. It is basically taking "snapshots" of probable operating conditions which can be used to validly point out the mechanism of voltage collapse for different operating conditions. Some of the existing methods used in static voltage stability analysis are PV and QV curves, sensitivity analysis, singular value decomposition, continuation power flow method (CPF), and modal analysis $[12,15,16,23]$. Features of these methods are summarized in Table 3.

PV and QV curves are among the most popular methods when it comes to static voltage stability analysis. PV curves are plots of load bus voltage magnitudes against load active power for a given power factor, whereas QV curves are plots of voltage against the reactive power injected into a bus. Static voltage stability analysis with these curves involves finding the extremes of these curves (nose points) by load flow calculations, where the distance between the current operating points and the extremes is the stability criterion. These curves only give the proximity to voltage collapse points but do not give information about the causes of voltage instability. Continuation power flow (CPF) method was proposed by Ajjarapu and Christy in $[24,25]$. This method overcomes the challenges that arise with power flow convergence when using PV curves, as computation approaches the nose points or voltage collapse point. To resolve these power flow convergence issues, $\mathrm{CPF}$ utilizes the predictor-corrector process to find the next operating point. The major shortcomings of PV, QV curves, and $\mathrm{CPF}$ method are the required computational effort and time since they are only related to a specific bus.

The singular value decomposition method is used to determine voltage stability margin by observing how close the Jacobian matrix of the power flow equations is, to becoming singular. In the analysis, the load is increased and the power flow Jacobian matrix, $J$, computed [26]. The loadability limit is reached when the smallest singular value of determinant of $J$ becomes 0 . This method cannot find a specific cause for voltage instability but provides a relative proximity to the voltage stability limit. Even though singular value decomposition is based on linearized power flow equations, the Jacobian matrix of power flow equations has a high degree of nonlinearity after stable operating point to the bifurcation point; hence, it is very difficult to evaluate the relative degree of voltage stability.
Sensitivity analysis is based on the sensitivity matrix derived from power flow equations. The sensitivity parameters are determined by the relationship between state variables and control variables [17]. An increase in the sensitivity coefficients usually indicates a power network is moving towards instability. Sensitivity analysis is a simple and clear method that provides a good judge when assessing the static voltage stability status of a power system and identifying the voltage weak points of the network. However, in complex networks, the linear characteristic of the sensitivity index prevents it from clearly reflecting the critical state of a system.

Modal analysis was proposed by Gao et al. [27] to predict voltage collapse in complex power networks. It is based on a linear approximation of the steady-state system model. It involves computing the smallest eigenvalues and associated eigenvectors of the reduced Jacobian matrix obtained from the load flow solution. The eigenvalues are associated with a mode of voltage and load variation which can provide a relative measure of stability. The eigenvalues and eigenvectors are used to calculate bus, branch, and generator participation factors. Bus participation factors identify voltage weak buses and corresponding load regions most susceptible to instability in a power network; branch participation factors indicate branches that cause the various modes to be weak (they are either weak links or heavily loaded), and generator participation factors provide important information regarding the distribution of reactive reserves among all machines in a network so as to maintain an adequate stability margin. Modal analysis can either be approached through QV or PV modal analysis with most literature focusing on QV modal analysis since it produces more accurate results for participation factors. This is because $Q$ is directly related to voltage magnitude $[16,27,28]$.

In the recent past, several studies have been carried out on voltage stability analysis and improvement using the conventional methods presented in this paper. PV and QV curves via the voltage stability margins index, sensitivity analysis, and modal analysis are employed in [29-37] in the analysis of voltage stability. However, because of the drawbacks of some of these methods as discussed in Table 3, further studies have been carried out employing the combination of one or more methods so as to get more information and greater degree of accuracy in voltage stability studies. Mao et al. [38-40] use a combination of powervoltage curves and modal analysis in the voltage stability assessment of power systems with the later focusing on a microgrid system. In $[41,42]$, the voltage stability sensitivity index is used to identify the weakest bus in the IEEE 14 bus system which is further analysed using power-voltage curves to identify the voltage collapse point. Reactive power compensation is also explored on the voltage weak buses. Voltage stability assessment through the integration of modal analysis and sensitivity analysis techniques is further presented in [43-45]. Puppala and Chandrarao [46] investigate voltage stability analysis using CPF, modal analysis, linear regression, and artificial neural networks for different loading conditions. Similarly, in [47-54], the various methods and indices are used in assessing the voltage stability in power 
TABLE 2: Summary of popular dynamic voltage stability analysis methods.

\begin{tabular}{|c|c|c|c|}
\hline Method & Features & Advantages & Limitations \\
\hline $\begin{array}{l}\text { Small signal } \\
\text { stability } \\
\text { analysis }\end{array}$ & $\begin{array}{l}\text { Involves analysing eigenvalues of the } \\
\text { linearized differential-algebraic } \\
\text { equations that describe the dynamic } \\
\text { model of a system. }\end{array}$ & $\begin{array}{l}\text { It provides information about the } \\
\text { inherent dynamic characteristics of a } \\
\text { system. }\end{array}$ & $\begin{array}{l}\text { Difficulty in establishing the main } \\
\text { components of a system and } \\
\text { modelling an accurate load model. }\end{array}$ \\
\hline $\begin{array}{l}\text { Time domain } \\
\text { simulation }\end{array}$ & $\begin{array}{l}\text { Involves solving the nonlinear } \\
\text { differential-algebraic equations, } \\
\text { continuous-discrete time equations } \\
\text { that describe the dynamic model of a } \\
\text { system. }\end{array}$ & $\begin{array}{l}\text { It is suitable for any power system } \\
\text { dynamic model and can be employed to } \\
\text { evaluate the effectiveness of other voltage } \\
\text { stability assessment methods. }\end{array}$ & $\begin{array}{l}\text { Difficulties arising from processing } \\
\text { time frame and load modelling. } \\
\text { Different load models yield different } \\
\text { conclusions. } \\
\text { A significant computational effort is } \\
\text { required. }\end{array}$ \\
\hline $\begin{array}{l}\text { Energy } \\
\text { function } \\
\text { method }\end{array}$ & $\begin{array}{l}\text { Employs Lyapunov direct method to } \\
\text { assess the stability of the system. }\end{array}$ & $\begin{array}{l}\text { Provides a quantitative measure of } \\
\text { voltage stability by showing the distance } \\
\text { between the current operating point and } \\
\text { the point of voltage collapse. }\end{array}$ & $\begin{array}{l}\text { Difficulty in constructing a proper } \\
\text { energy function due to the many } \\
\text { factors that affect the voltage stability } \\
\text { problem. }\end{array}$ \\
\hline
\end{tabular}

TABLE 3: Summary of popular static voltage stability analysis methods.

\begin{tabular}{|c|c|c|c|}
\hline Method & Features & Advantages & Limitations \\
\hline $\begin{array}{l}\text { PV and QV curves } \\
{[12]}\end{array}$ & $\begin{array}{l}\text { They are plots denoting load bus } \\
\text { voltage magnitudes for power } \\
\text { increased in a particular PQ bus. The } \\
\text { stability criterion is the "distance" } \\
\text { between the current operating point } \\
\text { and the extremes of these curves. }\end{array}$ & $\begin{array}{l}\text { The curves give a quantitative } \\
\text { measurement of the proximity to } \\
\text { voltage collapse. } \\
\text { QV curves give the reactive power } \\
\text { injection or absorption for various } \\
\text { scheduled voltages, which is } \\
\text { particularly useful when it comes to } \\
\text { sizing of shunt capacitors. } \\
\text { The loadability limits of buses can be } \\
\text { determined. }\end{array}$ & $\begin{array}{l}\text { They are bus specific methods, and } \\
\text { hence a large system would require a } \\
\text { lot of computational effort. } \\
\text { Convergence problems tend to occur as } \\
\text { loading on the system approaches the } \\
\text { voltage collapse point; hence, it is not } \\
\text { possible to know exact point of voltage } \\
\text { collapse. } \\
\text { Fails to give useful information about } \\
\text { the causes of voltage instability. }\end{array}$ \\
\hline $\begin{array}{l}\text { Continuation power } \\
\text { flow (CPF) }[24,25]\end{array}$ & $\begin{array}{l}\text { It is a technique used for tracing the } \\
\text { whole of a PV curve by finding the } \\
\text { next stable operating point for a } \\
\text { given load or load change scenario. } \\
\text { It utilizes the predictor-corrector } \\
\text { method. }\end{array}$ & $\begin{array}{l}\text { Provides a quantitative measure on } \\
\text { the proximity to voltage collapse. } \\
\text { Overcomes convergence problems } \\
\text { that arise with the use of PV and QV } \\
\text { curves; hence, one can determine } \\
\text { critical points of where voltage } \\
\text { collapse occurs accurately. }\end{array}$ & $\begin{array}{l}\text { Does not give information about the } \\
\text { causes of voltage instability. } \\
\text { Bus specific, which makes it } \\
\text { computationally intensive and time } \\
\text { consuming. }\end{array}$ \\
\hline
\end{tabular}

Utilizes the Jacobian matrix of a Singular value system where the determinant of the decomposition [26] matrix is calculated for load increments until it reaches a minimum value.

Provides a relative proximity to the voltage stability limit

Does not provide information on the causes of voltage instability.

Does not give an absolute measure of the voltage collapse point.

Based on the sensitivity matrix

derived from power flow equations. Provides a good judge on the voltage

Sensitivity analysis The sensitivity parameters are

[17]

determined by the relationship

between state variables and control variables.

It involves computing the smallest eigenvalues and associated

eigenvectors of the reduced Jacobian

matrix obtained from the power flow solution.

Modal analysis [27] The eigenvalues and eigenvectors are used to calculate bus, branch, and generator participation factors which identify the cause of instability.
The linear characteristics of the sensitivity index are not good especially for complex power systems; hence, it cannot accurately reflect the critical state of a system.
Gives information regarding the voltage stability status of a system from a system wide perspective both proximity to voltage collapse and mechanism of instability.

Identifies load regions most susceptible to voltage instability, weak buses and critical links in the network.
Eigenvalues do not provide an absolute measure of the proximity to voltage collapse. 
systems with renewable energy integration. Sizing and placement of FACTs devices are also investigated by the authors.

Several voltage stability indices (VSIs) have also been suggested over the past few decades, referred to either as bus or line have been proposed for both online and off-line studies, although most literature focuses on standard IEEE bus test systems. They are used to determine the proximity of a given operating point to voltage collapse. Some of the VSIs include Voltage Collapse Point Indicator (VCPI) and Line Stability Index, $L_{\mathrm{mn}}$ [55], Voltage Stability Index, $L$ [56], Fast Voltage Stability Index (FVSI)) [57], Voltage Reactive Power Index (VQI), and Line Stability Factor (LQP) in [58], and respectively [59]. The authors in [60-63] present a review of the voltage stability indices that have been proposed over the years.

In this paper, a methodology is proposed involving the combination of QV modal analysis, sensitivity analysis (VQ), and power-voltage curves used to assess the static voltage stability status of the Kenyan Power Network. Modal analysis is first used because it gives a system wide perspective on the voltage stability status of the system and identifies the causes of instability in the system, i.e., critical lines and weak buses. VQ sensitivity analysis is further employed to identify buses with large sensitivities in the system. The buses obtained by VQ sensitivity analysis are compared with those obtained through QV modal analysis. Power-voltage curves are then generated for the voltage weak buses identified by the two methods to get a measure of the proximity of these buses to voltage collapse using loading margins and voltage stability margins. The scripts used in generating the PV and QVs employ a predictor-corrector approach in generating the curves. A contingency study is also done to assess the static voltage stability status of the system by tripping one of the lines serving the main load region in the network.

This paper is organised as follows: Section 2 presents a brief literature review on the methods used, Section 3 presents an overview of the model of Kenyan Power Network under study and the methodology used, Section 4 presents the results obtained, the accompanying discussions, and an analysis of the results, and finally, Section 5 provides the conclusions of the study.

\section{Literature Review}

2.1. $P V$ and $Q V$ Curves. $P V$ and QV curves define the steadystate loadability limits which are related to voltage stability. They show the dependence of bus voltage magnitude on the active power load in a bus when increased from zero to its maximum possible value. Figure 1 shows a PV curve. The load is increased gradually and with each increment power flows are calculated until the nose of the PV curve is reached. At the nose point, further load increase provides no feasible operating voltage magnitude and it is the point where voltage collapse usually occurs. This limited load value is called the maximum loadability and the corresponding voltage is called the critical voltage $[11,12]$.

QV curves are plots of voltage against reactive power injected into a bus. They are generated by converting PQ buses into PV buses with open VAr limits, usually by applying fictitious VAr sources to the buses. QV curves show the reactive power injection or absorption for various scheduled voltages. Figure 2 shows a normalised QV curve. The $y$-axis shows the amount of reactive power that must be injected or absorbed for a bus to operate at a specific voltage. The operating point is the intersection of the curve with the $x$-axis. By themselves, QV curves can be used as an index for voltage instability; if the slope of the curve at the intersection is positive, then the system is stable since any additional reactive power will raise the voltage, and vice versa. The point where $\mathrm{d} Q / \mathrm{d} V=0$ corresponds to the nose point of the curve. If the minimum point is above the horizontal axis, it indicates a reactive power deficiency and additional reactive power sources are needed to prevent a voltage collapse scenario $[11,12]$.

Since the stability criterion when using PV and QV curves in voltage stability analysis involves determining the margin between the current operating point and the nose points of the curves, analysis can be done using loading margins and voltage stability margins. For a PV curve, the active power margin is the "distance" of active power from the operating point to nose point of the curve, and for a QV curve, the reactive power margin is the "distance" of reactive power from the operating point to the nose point. These margins are computed using equations (1) and (2), respectively:

$$
\begin{aligned}
& L M(P)=P_{\text {critical }}-P_{\text {operating }}, \\
& L M(Q)=Q_{\text {critical }}-Q_{\text {operating }},
\end{aligned}
$$

where $P_{\text {critical }}$ and $Q_{\text {critical }}$ are the values of load active and reactive powers at the nose point of the curves and $P_{\text {operating }}$ and $Q_{\text {operating }}$ are the load values at the operating point.

Voltage stability margin (VSM) of a bus can be defined as the "distance" between the initial voltage operating point until the voltage critical/collapse point. It is obtained from both PV and QV curves [15]. Conventionally, VSM is calculated using the following equation:

$$
\mathrm{VSM}=\frac{V_{\text {initial }}-V_{\text {critical }}}{V_{\text {critical }}},
$$

where $V_{\text {initial }}$ is initial bus operating voltage and $V_{\text {critical }}$ is the bus voltage at the voltage collapse point.

However, equation (3) fails to account for the load increments that occur during generation of PV and QV curves which can result in two dissimilar buses have same or close to same VSM values. To overcome this, some literatures [64] propose the determination of the voltage stability margin by measuring the hypotenuse distance of the triangle under the PV and QV curves as shown in Figures 3 and 4.

From Figures 3 and 4,

$$
\begin{aligned}
& \text { VSM, } P=\sqrt{a^{2}+b^{2}}, \\
& \operatorname{VSM}, Q=\sqrt{C^{2}+d^{2}},
\end{aligned}
$$

where $a=V_{\text {pinitial }}-V_{\text {pcritical }}, \quad b=P_{\text {operating }}-P_{\text {critical }}, c=V$ qinitial $-V_{\text {qcritical }}$, and $d=Q_{\text {operating }}-Q_{\text {critical }}$. 


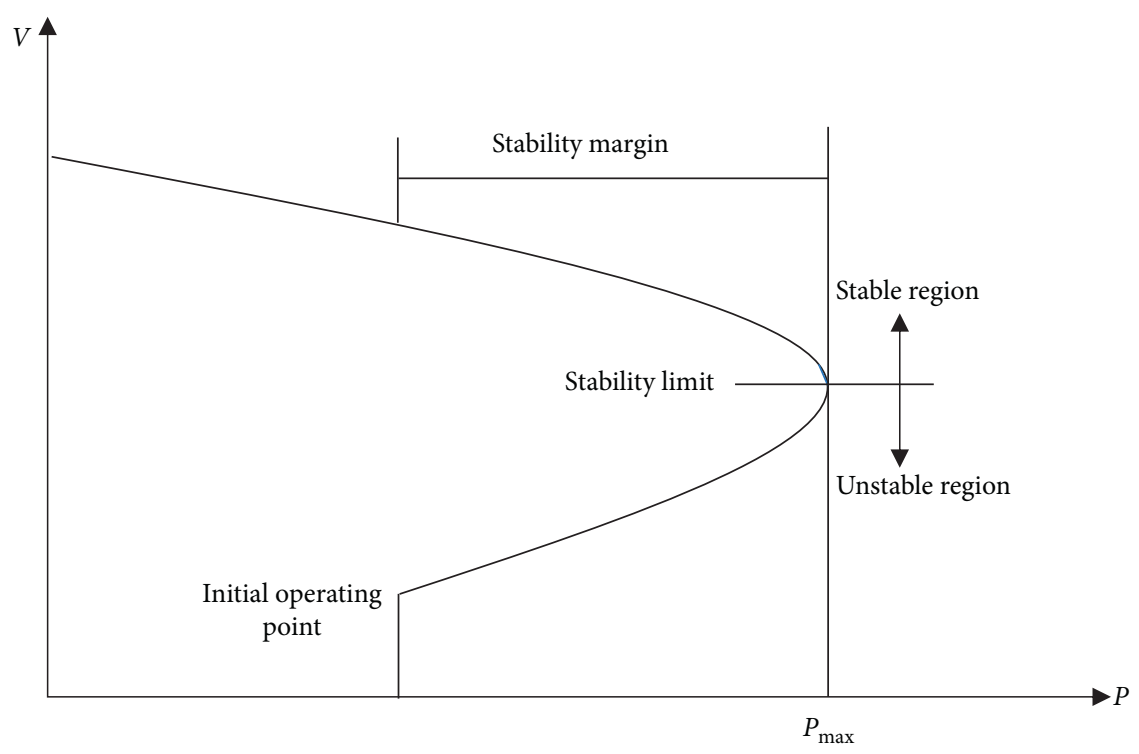

Figure 1: PV curve.

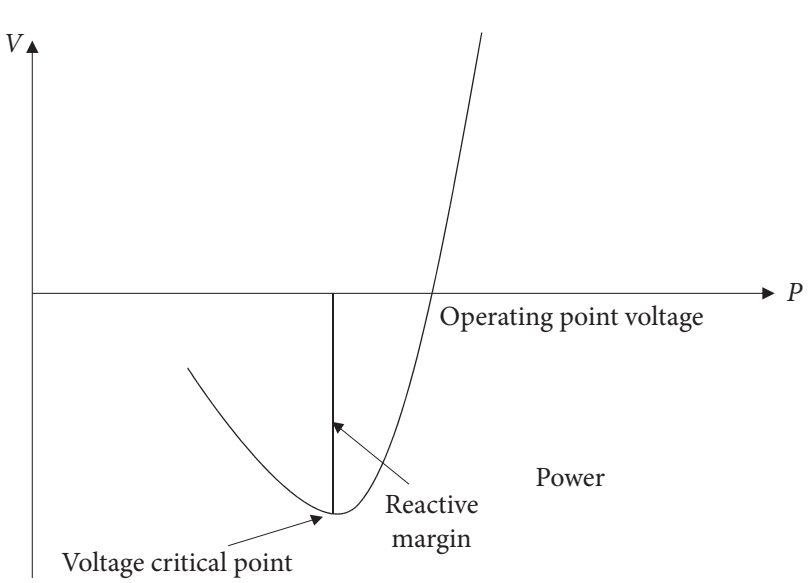

FIgURE 2: Normalised QV curve.

2.2. VQ Sensitivity Analysis. VQ Sensitivity analysis is based on the power flow equations and the Jacobian matrix. The power flow problem can be formulated as follows [12]:

$$
\left[\begin{array}{c}
\Delta P \\
\Delta Q
\end{array}\right]=[J]\left[\begin{array}{c}
\Delta \delta \\
\Delta V
\end{array}\right]
$$

where $\Delta P$ and $\Delta Q$ are the mismatch active and reactive powers, $\Delta \delta$ and $\Delta V$ are the incremental changes in the bus voltage angle and magnitude, respectively, and $J=\left[\begin{array}{ll}J_{P \delta} & J_{P V} \\ J_{\mathrm{Q} \delta} & J_{\mathrm{QV}}\end{array}\right]$ is the Jacobian matrix.

The $i^{\text {th }}$ diagonal element of the matrix $\left[J_{\mathrm{QV}}\right]$ represents the VQ sensitivity of the load bus $i$ when considering changes in active and reactive powers. System voltage stability is affected by both $P$ and $Q$. However, at each operating point, if $P$ is kept constant and voltage stability is evaluated by considering incremental relationship between $Q$ and $V$. Based on these considerations and letting $\Delta P=0$, equation (6) becomes

$$
\begin{aligned}
{\left[\begin{array}{c}
0 \\
\Delta Q
\end{array}\right] } & =[J]\left[\begin{array}{c}
\Delta \delta \\
\Delta V
\end{array}\right], \\
\Delta Q & =J_{R} \Delta V,
\end{aligned}
$$

where,

$$
J_{R}=\left[J_{Q V}-J_{Q \delta} J_{P \delta}^{-1} J_{P V}\right] .
$$

Equation (8) is the linearized power flow equation. $J_{R}$ is the reduced Jacobian matrix of the system. It is the matrix that directly relates bus reactive power injection and bus voltage magnitude. From equation (7),

$$
\Delta V=J_{R}^{-1} \Delta Q \text {. }
$$

The matrix $J_{R}^{-1}$ is the reduced V-Q Jacobian, and its $i^{\text {th }}$ diagonal element is the sensitivity at bus $-i$. The $\mathrm{V}-\mathrm{Q}$ sensitivity at a bus represents the slope of Q-V curve at a given operating point. A positive $\mathrm{V}-\mathrm{Q}$ sensitivity is indicative of stable operation; the smaller the sensitivity, the more stable the system. As the stability decreases, the magnitude of the sensitivity increases, becoming infinite at the stability limit. Conversely, a negative sensitivity is indicative of unstable operation. A small negative sensitivity represents a very unstable operation [12].

2.3. QV Modal Analysis. In QV modal analysis, the voltage stability characteristics of a system are identified by computing the eigenvalues and eigenvectors of the power flow reduced Jacobian matrix, $J_{R}[12,16,27]$. It is represented by eigenvector matrices as shown in the following equation:

$$
J_{R}=\xi \Lambda \eta
$$

where $\xi$ is the right eigenvector matrix of $J_{R}, \eta$ is the left eigenvector matrix of $J_{R}$, and $\Delta$ is the diagonal eigenvalue matrix of $J_{R}$ 


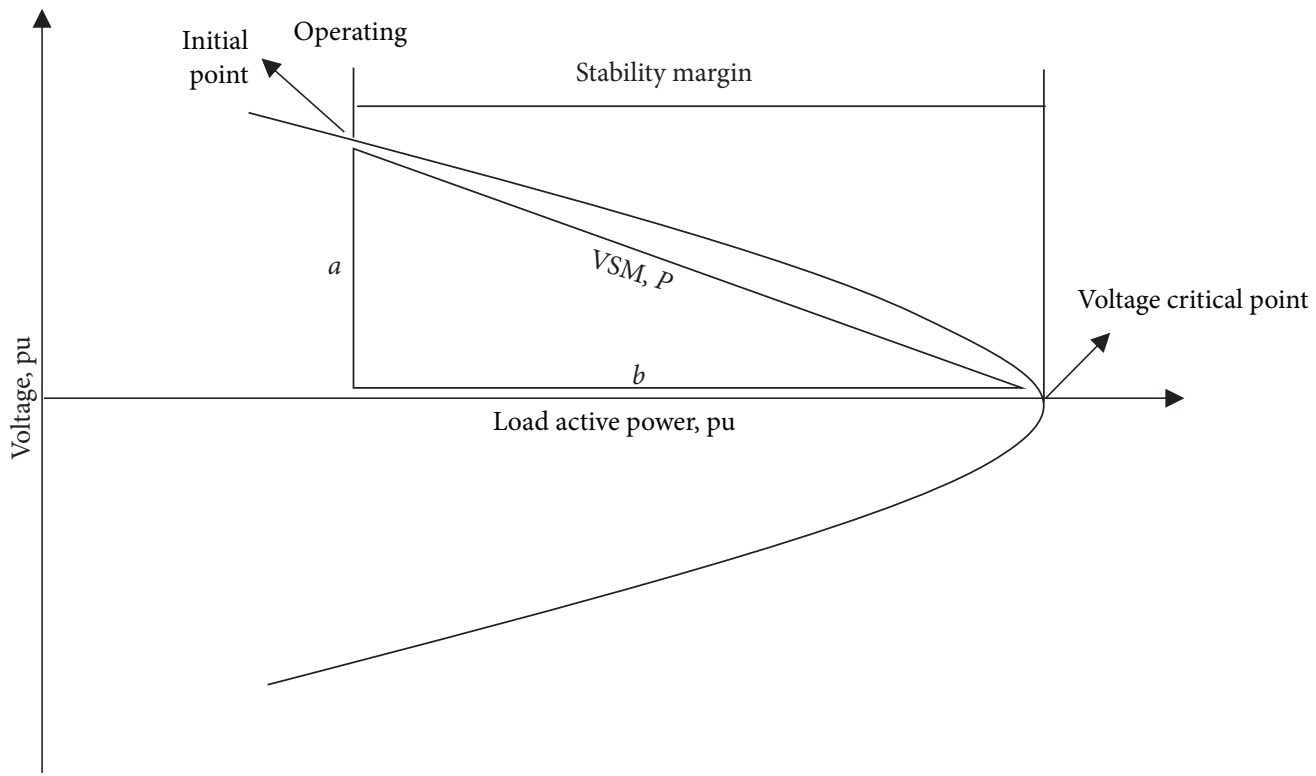

Figure 3: VSM Computation from PV curve.

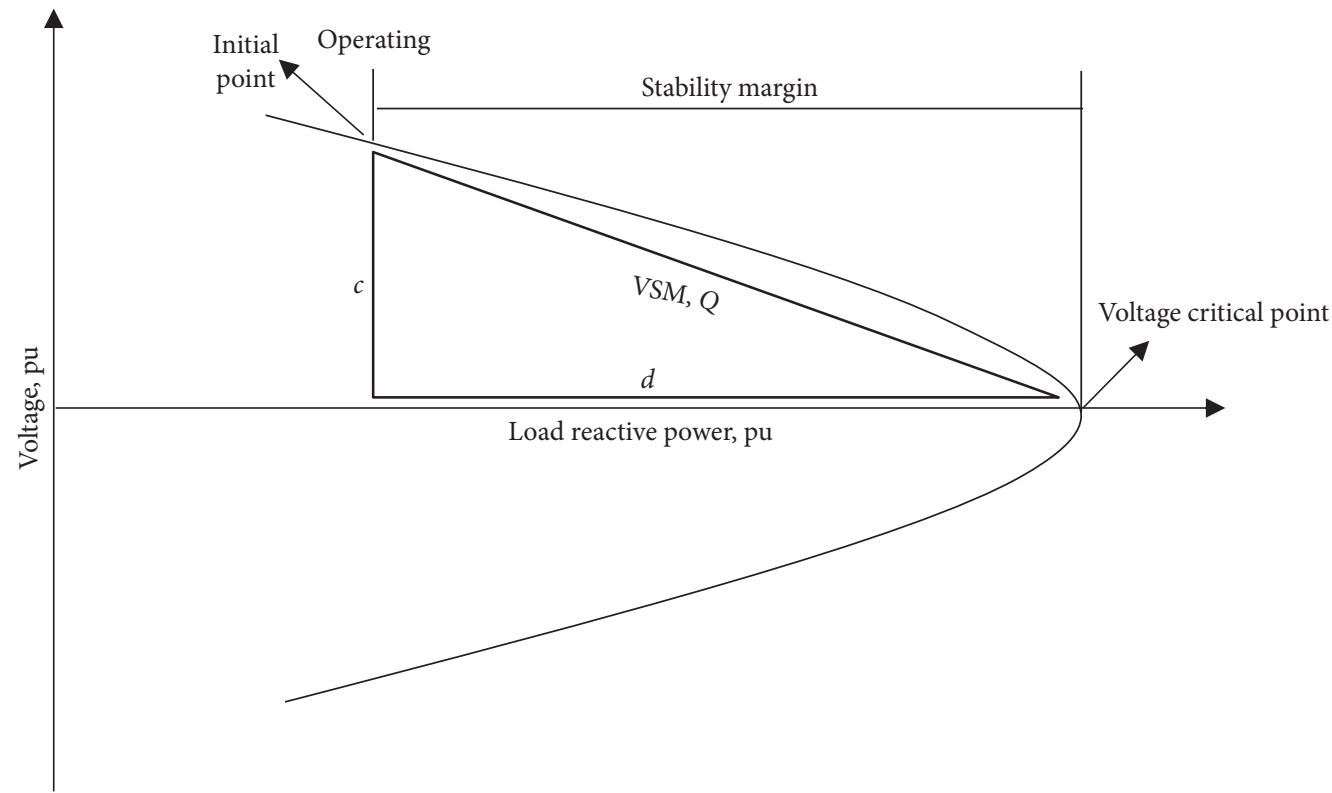

Figure 4: VSM Computation for QV curves.

From equation (11), the reduced Jacobian matrix $J_{R}$ can be expressed as

$$
\begin{aligned}
J_{R}^{-1} & =\xi \eta \Lambda^{-1} \\
\xi \eta & =I .
\end{aligned}
$$

Equation (11) then becomes

$$
\Delta V=\xi \eta \Lambda^{-1} \Delta Q
$$

or

$$
\Delta V=\sum_{i} \frac{\xi_{i} \eta_{i}}{\lambda i} \Delta Q
$$

where $\lambda_{i}$ is the $i^{\text {th }}$ eigenvalue, $\xi_{i}$ is the $i^{\text {th }}$ column right eigenvector, and $\eta_{i}$ is the $i^{\text {th }}$ row left eigenvector of the reduced Jacobian matrix. Each eigenvalue, corresponding right and left eigenvectors, defines a mode of $\mathrm{V}$-Q response.

Similarly, from $\xi \eta=I, \xi^{-1}=\eta$. Therefore, equations (13) and (14) can be expressed as

$$
\eta \Delta V=\eta \wedge^{-1} \Delta Q
$$

or

$$
v=\Lambda^{-1} q
$$

where $v=\eta \Delta V$ is the vector of modal voltage variations and $q=\eta \Delta Q$ is the vector of modal reactive power variations. 
The corresponding $i^{\text {th }}$ modal voltage variation is given by

$$
v_{i}=\frac{1}{\lambda_{i}} q_{i}
$$

From equation (17), the stability of mode $i$ with respect to reactive power changes is defined by the modal eigenvalue. Large values $\lambda_{i}$ of suggest small changes in modal voltage for reactive power changes. As the system is stressed, the value of $\lambda_{i}$ becomes smaller and the modal voltage becomes weaker. If the magnitude of $\lambda_{i}$ is equal to zero, the corresponding modal voltage collapses since it undergoes infinite changes for reactive power changes. A system is therefore defined as voltage stable if all the eigenvalues of the reduced Jacobian matrix are positive. The bifurcation or voltage stable limit is reached when at least one eigenvalue reaches zero, that is, one or more modal voltages collapses. If any of the eigenvalues is negative, the system is unstable. The magnitudes of eigenvalues provide a relative measure of the proximity of the system to instability [12].

There is no need to evaluate all the eigenvalues of the $J_{R}$ of a large power system, because once the minimum eigenvalue becomes zero, the system Jacobian matrix becomes singular and voltage instability occurs. On the other hand, evaluating only the minimum eigenvalue of $J_{R}$ is not sufficient because there is usually more than one mode associated with different parts of the system, and the mode associated with the minimum eigenvalue may not be the most troublesome mode as the system is stressed [12]. Therefore, evaluating 5-10 of the smallest eigenvalues usually gives sufficient information on the voltage stability status of the system.

Bus Participation Factors. In mode $i$, the participation of bus $k$ is defined by

$$
P_{k i}=\xi_{i k} \eta_{k i}
$$

The bus participation factor determines the contribution of $\lambda i$ to the VQ sensitivity at bus $k$. A high value of $P_{k i}$ at bus $k$ for mode $i$ means this bus is close to voltage instability in this mode. Therefore, the bus participation factors of the critical modes can be used to determine weak buses and predict areas in the system most prone to instability.

Branch Participation Factors. The relative participation of branch $j$ in mode $i$ is given by the participation factors:

$$
P_{j i}=\frac{\Delta Q_{\text {loss }} \text { for branch } j}{\max \Delta Q_{\text {loss }} \text { for all branches }} .
$$

Branches with high participation factors indicate which branches consume the most reactive power in a network for a given incremental change in reactive load. They are either weak links or heavily loaded. Branches with high participation factors in the critical mode are identified as critical branches. Branch participation factors provide valuable information that can be used in contingency selections during contingency studies and how to enhance the transmission lines and redistribute power flows so as to alleviate loading on overloaded lines.

\section{Case Study}

3.1. Kenyan Power System. The Kenyan power system is rapidly developing, with loading conditions changing relatively fast. Currently, the system has an installed generation capacity of about $3 \mathrm{GW}$ with a peak load demand slightly above $1.9 \mathrm{GW}$ as of the last quarter of 2019. In this paper, a 330 -bus model of the system was developed and used as the study case. The model consists of 97 substations with 20 of them being generating substations. It has 185 transmission lines transmitting power at $66 \mathrm{kV}, 132 \mathrm{kV}$ and $220 \mathrm{kV}$ with the aid 184 2-winding transformers and 29 3-winding transformers all modelled with load tap changers. The model has a total installed capacity of $2.9268 \mathrm{GW}$ with an effective (grid connected) capacity of $2.14643 \mathrm{GW}$ and a load demand of $1.58859 \mathrm{GW}$. Figure 5 shows a single line diagram of the model as seen in DigSILENT PowerFactory. A schematic for the same is provided alongside the supplementary data.

In carrying out this study, load flow analysis was performed while neglecting the effect of transformer load tap changers since this is a static voltage stability study. The aim of the load flow study was to determine the voltage profile of the test system. QV modal analysis was then carried out to identify the eigenvalues and eigenvectors of the system. As discussed in Section 2, the minimum eigenvalues which correspond to critical modes of the network which were then selected and evaluated to obtain weak buses in the system and also predict load regions most susceptible to instability. Reactive power loss sensitivity factors $\partial Q_{\text {loss }} / \partial Q$ were then selected as a criterion for identifying critical lines in the network. The transmission lines with the highest reactive power loss sensitivity factors for each of the critical modes analysed were then determined. VQ sensitivity analysis was then carried out on the system to identify buses that undergo large voltage changes for reactive power imports in the system. A comparison was then made between the buses with the highest participation factors identified in each of the Q-Modes and the sensitivities of these buses.

The load buses identified as having the highest participation factors were further investigated using voltage stability margins discussed in Section 2 to determine the proximity of the buses towards instability. VSM values of these buses were determined through generation of PV and QV curves for the respective load buses. The loading margins of these buses were also computed to determine how much active or reactive power could be absorbed from these buses before voltage instability occurs.

The effect on the static voltage stability of the system with the removal of a line was also investigated. The eigenvalues of the system after contingency were determined. The resultant effect on the voltage stability margins of the load buses with the highest participation factors was also determined.

3.2. Methodology. QV modal analysis was carried out using the load flow sensitivities tool in DigSILENT PowerFactory. By default, DigSILENT PowerFactory provides eigenvalues in the form $\lambda^{-1}$, ranking them in descending order of 


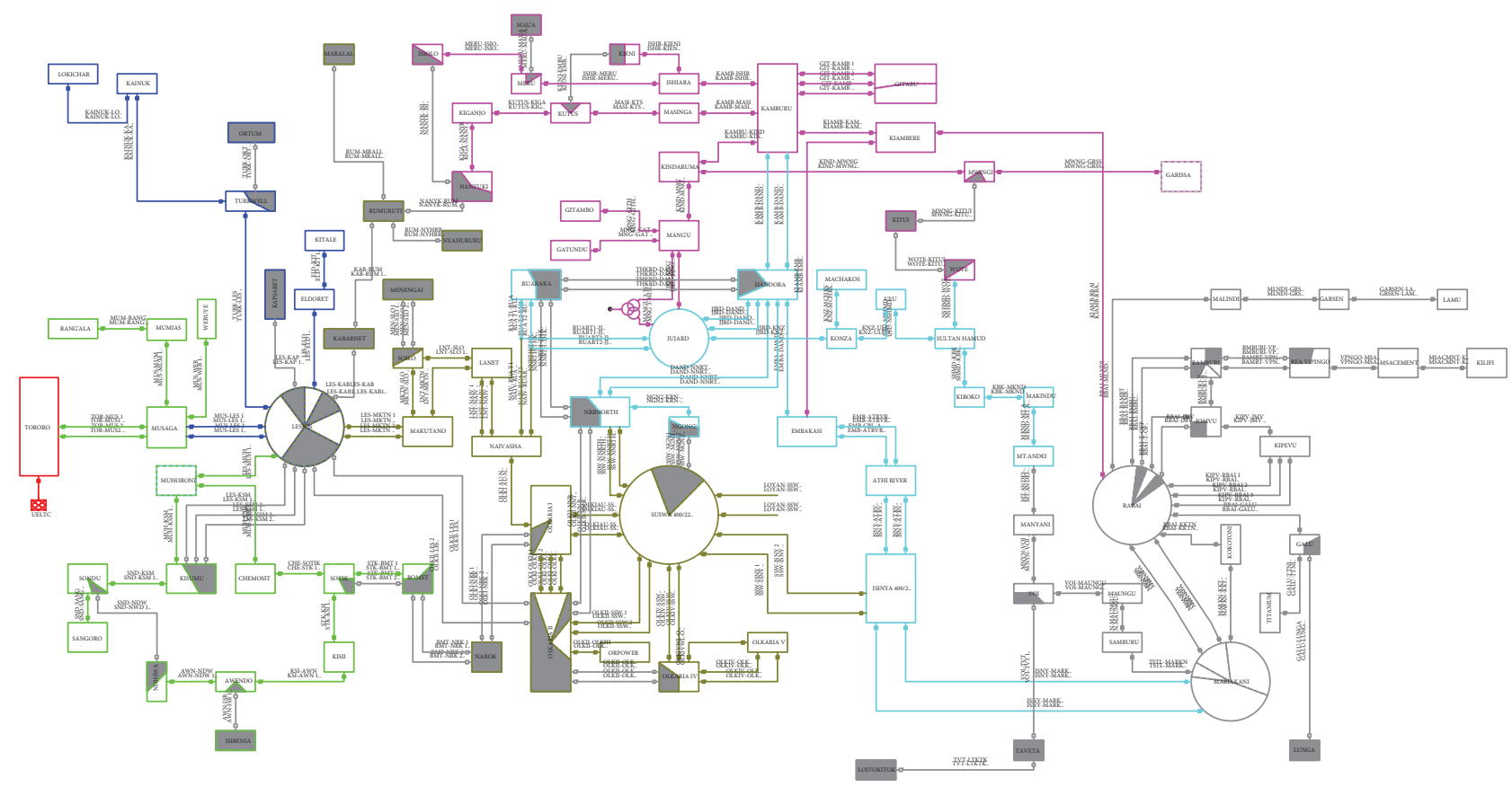

Figure 5: Kenyan transmission network.

magnitude. Therefore, the eigenvalues with the largest magnitudes correspond to the critical modes of the system. In this study, the eigenvalues which correspond to the 5 critical modes were evaluated. Evaluation of these modes would suffice in getting a detailed "snapshot" of the voltage stability status of the system. Evaluation of the 5 critical modes involved determining the buses with the highest participation factors in each of the critical modes. These participation factors identify buses participating in making the identified modes weak. These are weak buses in the system. Since each mode can be associated with different parts of the system, load regions most susceptible to instability were also identified. In the identification of the critical lines in the network, reactive power loss sensitivities for the transmission lines were determined for each of the Q-modes. The sensitivities identified the lines that consumed more reactive power for reactive power imports in the system. Similarly, lines that supplied reactive power to the system for reactive power imports in each Q-Mode were also determined.

VQ sensitivity analysis involved determining the diagonal elements of the inverse reduced Jacobian matrix of the system. The VQ sensitivities identify the buses that experience large voltage changes for reactive power variations in the system. These can be categorised as weak buses because a large absorption of reactive power from those buses results in large declines on the bus voltages.

The load buses (rated $3.3 \mathrm{kV}$ to $33 \mathrm{kV}$ ) identified as having the highest participation factors in the critical Q-Modes were further analysed using voltage stability margins obtained from the buses' PV and QV curves. This was to determine the proximity to voltage collapse of these buses. It identified the buses closest to instability among the identified buses in the test network. The PV and QV curves of these buses were generated using DIgSILENT Powerfactory's U-P and U-Q command scripts. The U-P script generates a PV curve for a selected load bus by incrementally varying the selected load until the power flow does not converge. A QV curve on the other hand is generated by applying a fictitious VAr source at the selected bus, i.e., converting the bus to a PV bus with open VAr limits and then the U-Q script is then executed. It automatically generates a QV curve by performing power flow for various set points until the load flow fails to converge. The loading margins of these buses were also determined.

A contingency study is also done to assess the voltage stability of the test system. The $N-1$ contingency was selected as a criterion for the study, in which a line outage was simulated. A line was selected which is of crucial importance to the system but not directly associated with the load regions identified.

\section{Results and Discussions}

The system has 506 eigenvalues which correspond to different modes of VQ responses in the test system under this particular configuration of the system. The 5 critical modes were determined and analysed. The modes are presented as Q-Modes 1-5 with Q-mode 1 being the most critical. Negative eigenvalues were also obtained; they indicate the system is voltage unstable and in the event of a disturbance, voltage instability or even voltage collapse could occur without correct preventive measures. Table 4 presents the eigenvalues corresponding to the most critical modes and the modes with negative eigenvalues. A comparison of the buses with the highest participations in the critical Q-modes evaluated and VQ sensitivities of the buses was done as presented in Table 5. 
TABLE 4: Test system eigenvalues.

\begin{tabular}{lccccc}
\hline & \multicolumn{2}{c}{ Smallest eigenvalues } & \multicolumn{2}{c}{ Negative eigenvalues } \\
Q-mode & $\lambda^{-1}$ & $\lambda$ & Q-mode & $\lambda^{-1}$ & \multicolumn{1}{c}{$\lambda$} \\
\hline 1 & 0.11958 & 8.3626 & 125 & -0.00099 & -1010.1010 \\
2 & 0.07303 & 13.6930 & 131 & -0.00083 & -1204.8192 \\
3 & 0.05448 & 18.3554 & 136 & -0.00071 & -1408.4507 \\
4 & 0.04723 & 21.1729 & 138 & -0.00055 & -1818.1818 \\
5 & 0.03075 & 32.5203 & 139 & -0.00055 & -1818.1818 \\
& & & 162 & -0.00019 & -5263.1579 \\
& & 167 & -0.00002 & -50000.0000 \\
& & & 168 & -0.00002 & -50000.0000 \\
\hline
\end{tabular}

TABLE 5: Buses with highest participation factors in their respective Q-Modes and their corresponding VQ sensitivities.

\begin{tabular}{|c|c|c|c|}
\hline Q-mode & Bus $(\mathrm{kV})$ & Participation factor & $\partial V / \partial Q$ \\
\hline \multirow{10}{*}{1} & MAUNGU $3.3 \mathrm{kV}$ & 0.02652228 & 0.02012250 \\
\hline & TITANIUM $11 \mathrm{kV}$ & 0.02494999 & 0.01221846 \\
\hline & MANYANI $6.6 \mathrm{kV}$ & 0.02405406 & 0.02060746 \\
\hline & VIPINGO 11 kV & 0.02386996 & 0.01816219 \\
\hline & MSA CEMENT $6.9 \mathrm{kV}$ & 0.02341129 & 0.00673793 \\
\hline & KILIFI $33 \mathrm{kV}$ & 0.02205738 & 0.00706953 \\
\hline & JOMVU $33 \mathrm{kV}$ & 0.02201498 & 0.00949466 \\
\hline & VOI $33 \mathrm{kV}$ & 0.02137203 & 0.01063525 \\
\hline & NEW MAUNGU $33 \mathrm{kV}$ & 0.02103045 & 0.01044835 \\
\hline & KILIFI $132 \mathrm{kV}$ & 0.02034632 & 0.00706953 \\
\hline \multirow{10}{*}{2} & NDHIWA $33 \mathrm{KV}$ & 0.09711623 & 0.01316023 \\
\hline & NDHIWA $132 \mathrm{kV}$ & 0.08257213 & 0.00773125 \\
\hline & AWENDO $33 \mathrm{kV}$ & 0.08222746 & 0.00947862 \\
\hline & KISII 33 kV & 0.07914968 & 0.00839135 \\
\hline & AWENDO $132 \mathrm{kV}$ & 0.07799981 & 0.00677692 \\
\hline & CHEMOSIT1 $33 \mathrm{kV}$ & 0.07215037 & 0.01148787 \\
\hline & CHEMOSIT2 $33 \mathrm{kV}$ & 0.06855242 & 0.01141655 \\
\hline & KISII $132 \mathrm{kV}$ & 0.06788263 & 0.00562183 \\
\hline & BOMET $33 \mathrm{kV}$ & 0.06749805 & 0.01097600 \\
\hline & BOMET $132 \mathrm{kV}$ & 0.05843952 & 0.00543924 \\
\hline \multirow{10}{*}{3} & SULTAN HAMUD $33 \mathrm{kV}$ & 0.08466116 & 0.01942419 \\
\hline & MTITO ANDEI $3.3 \mathrm{kV}$ & 0.05217599 & 0.02078821 \\
\hline & WOTE $33 \mathrm{kV}$ & 0.05117196 & 0.00833651 \\
\hline & ULU $6.6 \mathrm{kV}$ & 0.04865066 & 0.01712400 \\
\hline & NEW S.HAMUD $33 \mathrm{kV}$ & 0.04645101 & 0.00726506 \\
\hline & KIBOKO 33 kV & 0.04593115 & 0.00788178 \\
\hline & KIBOKO $132 \mathrm{kV}$ & 0.04533945 & 0.00355300 \\
\hline & MAKINDU $132 \mathrm{kV}$ & 0.04354971 & 0.00374664 \\
\hline & WOTE $132 \mathrm{kV}$ & 0.04326751 & 0.00391558 \\
\hline & SULTAN HAMUD $132 \mathrm{kV}$ & 0.04063330 & 0.00300149 \\
\hline \multirow{5}{*}{4} & LOKICHAR $33 \mathrm{kV}$ & 0.3300015 & 0.01934614 \\
\hline & LOKICHAR $66 \mathrm{kV}$ & 0.2591555 & 0.01422896 \\
\hline & KALEMNGOROK $33 \mathrm{kV}$ & 0.2375207 & 0.01881238 \\
\hline & KALEMNGOROK $66 \mathrm{kV}$ & 0.1450877 & 0.00865333 \\
\hline & TURKWELL 66 kV & 0.0282346 & 0.00350657 \\
\hline \multirow{4}{*}{5} & GARISSA $11 \mathrm{kV}$ & 0.3896302 & 0.01425841 \\
\hline & GARISSA $132 \mathrm{kV}$ & 0.2986784 & 0.01044549 \\
\hline & MWINGI 33 kV & 0.1792026 & 0.00973072 \\
\hline & MWINGI $132 \mathrm{kV}$ & 0.1324889 & 0.00564510 \\
\hline
\end{tabular}

Maungu, Ndhiwa, Sultan Hamud, Lokichar, and Garissa were identified to have the highest participation factors for Q-Modes 1-5, respectively. The buses associated with $\mathrm{Q}$-Mode 1 and 3 referred to the same load region. Since
Q-Modes 1-3 had many buses participating in making them weak, only a sample of the buses was taken, i.e., those having the highest participation factors. In the case of Q-Mode 4 and 5 , all the buses are presented. The VQ sensitivities of the 
TABLE 6: Branch reactive power loss sensitivity factors.

\begin{tabular}{|c|c|c|c|c|}
\hline Q-mode & Branch & $\begin{array}{c}\text { Reactive power loss } \\
\text { sensitivity (kVar/MVar) }\end{array}$ & Branch & $\begin{array}{c}\text { Reactive power loss } \\
\text { sensitivity (kVar/MVar) }\end{array}$ \\
\hline \multirow{5}{*}{1} & Embakasi-Dandora & 2.5094 & Isinya-Marikana $1 \& 2$ & -179.0624 \\
\hline & Musaga-Lessos 1 \& 2 & 0.8824 & Kiambere-Rabai & -124.9418 \\
\hline & Tororo-Musaga $1 \& 2$ & 0.3904 & Embakasi-NRB CBD $1 \& 2$ & -59.7014 \\
\hline & Ruaraka-Juja RD $1 \& 2$ & 0.0887 & Garsen-Lamu & -53.0434 \\
\hline & Lanet-Soilo & 0.0077 & Malindi-Garsen & -52.3661 \\
\hline \multirow{5}{*}{2} & Turkwel-Lessos & 45.4405 & Lessos-Muhoroni & -26.5927 \\
\hline & Sondu-Kisumu & 20.5669 & Musaga-Lessos 1 \& 2 & -9.5865 \\
\hline & Muhoroni-Chemosit & 18.4387 & Tororo-Musaga $1 \& 2$ & -4.2409 \\
\hline & Kisii-Awendo & 16.2914 & Chemosit-Sotik & -3.3538 \\
\hline & Awendo-Ndiwa & 15.1228 & Olkaria-Naivasha & -3.1632 \\
\hline \multirow{5}{*}{3} & Garsen-Lamu & 3.2492 & Embakasi-NRB CBD $1 \& 2$ & -13.4090 \\
\hline & Rabai-BamburiT & 2.3760 & Makindu-Mtito Andei & -8.4897 \\
\hline & Rabai-Galu & 2.2821 & Loiyangalani-Suswa 1 \& 2 & -6.5216 \\
\hline & Malindi-Garsen & 1.4510 & Isinya-Mariakani 1 \& 2 & -6.5088 \\
\hline & BamburiT-Vipingo & 1.2231 & Mtito Andei-Manyani & -5.9037 \\
\hline \multirow{5}{*}{4} & Musaga-Lessos 1 \& 2 & 3.3821 & Turkwel-Lessos & -51.833 \\
\hline & Tororo-Musaga $1 \& 2$ & 1.4962 & Kainuk-Kalemngorock & -35.5561 \\
\hline & Naivasha-Ruaraka 1 \& 2 & 0.7997 & Kainuk-Lokichar & -33.6592 \\
\hline & Kanburu-Githambo & 0.2816 & Lessos-Muhoroni & -5.2900 \\
\hline & Kiambere-Kamburu & 0.1256 & Isinya-Mariakani $1 \& 2$ & -3.6815 \\
\hline \multirow{5}{*}{5} & Kindaruma-Mwingi & 63.8303 & Mwingi-Garissa & -123.4273 \\
\hline & Kamburu-Kindaruma & 10.9145 & Isinya-Mariakani 1 \& 2 & -23.7598 \\
\hline & Musaga-Lessos 1 \& 2 & 0.3329 & Embakasi-NRB CBD $1 \& 2$ & -19.1630 \\
\hline & Tororo-Musaga $1 \& 2$ & 0.1473 & Kiambere-Rabai & -17.1482 \\
\hline & RuarakaT-Juja RD 1 \& 2 & 0.0592 & Loiyangalani-Suswa $1 \& 2$ & -9.16742 \\
\hline
\end{tabular}

network identify Mtito Andei a $3.3 \mathrm{kV}$ load bus as having the highest sensitivity of 0.02078821 p.u/MVar. The lowest VQ sensitivity determined was 0.0001433 p.u/MVar belongs to a $220 \mathrm{kV}$ busbar located in one of the generating stations in the network. All voltage-controlled buses had 0 sensitivities. Although, a direct comparison cannot be made between the VQ sensitivities and bus participation factors due the nonlinear nature of VQ relationships, the VQ sensitivities identified for the buses with the highest participation factors were the highest in the system. The supplementary data provided present the participation factors of all the buses associated with Q-modes 1-3.

The branches with the highest reactive power loss sensitivities in each of the Q-Modes evaluated are identified are presented in Table 6 . The positive reactive power loss sensitivities identify branches that consumed the most reactive power for reactive power imports in the system thus contributing to their respective modes being weak and the negative reactive power loss sensitivity identify branches that supplied reactive power in the network for their respective Q-Modes Failures in some of these lines could lead to low voltage scenarios or voltage collapses in significant parts of the system. The buses identified and lines identified present candidate locations for placement of FACTs devices in the system, especially when improving the voltage stability of the system is the objective.

From Table 5, the load buses (rated $3.3 \mathrm{kV}$ to $33 \mathrm{kV}$ ) identified as having the highest participation factors in the critical Q-Modes were further analysed using voltage stability margins obtained from the buses' PV and QV curves. Figures 6 and 7 present the PV and QV curve of Maungu $3.3 \mathrm{kV}$ load bus identified as having the highest participation factor in Q-Mode 1. From the PV and QV curves, the critical voltages and loading margins were obtained which facilitated the determination of the voltage stability margins. The power-voltage curves for the other selected buses in the table were also plotted and the voltage stability margins determined. Table 7 presents the loading margins and voltage stability margins of these buses.

The results obtained in Table 7 identify Titanium, Chemosit2, Mtito Andei, Lokichar, and Mwingi as being the buses closest to instability in their respective Q-Modes. Amongst the 5 buses, Chemosit2 was the buses closest to instability, having the lowest active and reactive power margins. The voltage of these load bus as identified by load flow analysis was $0.88131 \mathrm{pu}$, the lowest recorded in the system followed by Titanium identified in Q-Mode 1 which had a voltage of $0.89531 \mathrm{pu}$ which also happened to be the second bus closest to instability after Chemosit. These are buses in need of voltage support in the system and the weakest buses in the test network. Figure 8 presents a comparison between the bus voltages and voltage stability margins and of these weakest buses. The loading margins of these buses, also presented in Table 7, indicate the amount of active and reactive power that could be absorbed from these buses before voltage collapse occurs. It is worth noting that these margins exist in a simulation scenario, in a real situation, voltage instability occurs before the maximum load limit is reached. 


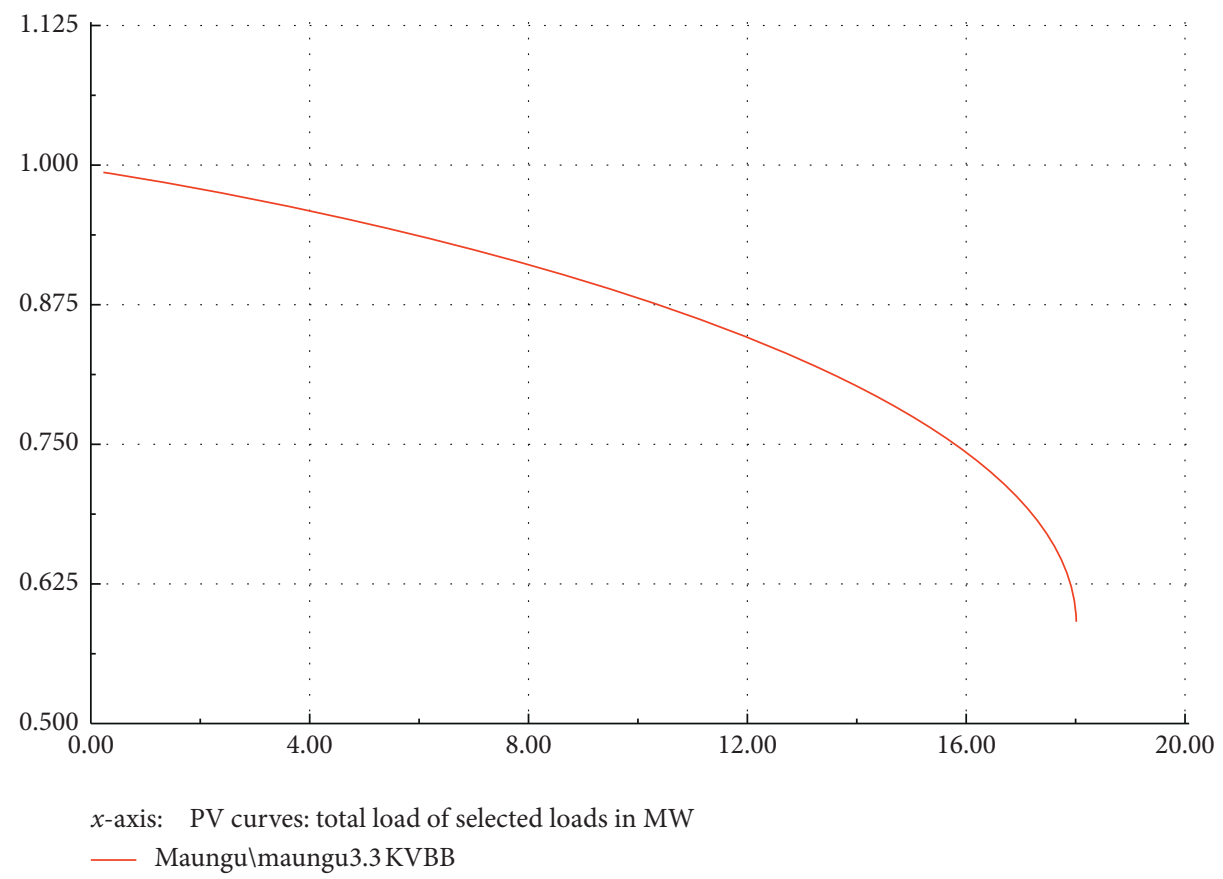

Figure 6: Maungu PV curve.

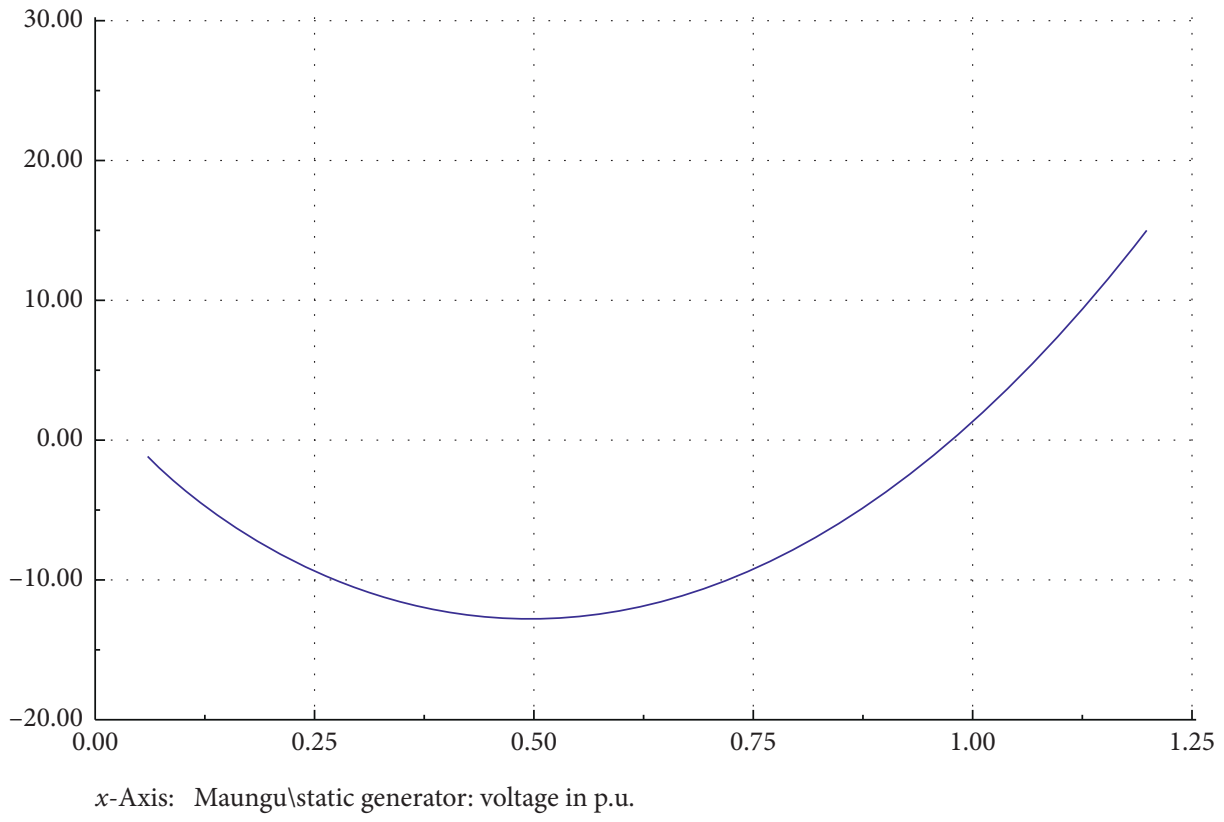

Figure 7: Maungu QV curve.

The contingency study was also conducted to assess the voltage stability of the test system using $\mathrm{N}-1$ criterion. Nairobi North to Dandora line was chosen arbitrarily. This is a double circuit line that serves the major load region in the network. It evacuates power from one of the main generating stations in the country to the most loaded region. In recent years, it has been noted as being one of the most troublesome lines in the network, where an outage in one of the lines usually leads to a cascade of events that eventually lead to a total collapse of the network. One of the Nairobi North to Dandora lines was thus removed from the network and the resultant effect on the static voltage stability of the test network assessed. The effect on the voltage stability margins of the load buses is also noted. Table 8 presents the data obtained with the removal of the line from the network.

From Table 8, it is observed that load regions 1 and 3 associated with Q-Modes 1and 3 are the most affected with 
TABLE 7: Loading margins and voltage stability margins of selected buses in critical modes.

\begin{tabular}{|c|c|c|c|c|c|}
\hline Q-mode & BUS & $\begin{array}{l}\text { Loading margin } \\
(\mathrm{MW})\end{array}$ & $\begin{array}{l}\text { Loading margin } \\
\text { (MVar) }\end{array}$ & $\begin{array}{c}\text { Active power-voltage } \\
\text { stability margin }\end{array}$ & $\begin{array}{c}\text { Reactive power-voltage } \\
\text { stability margin }\end{array}$ \\
\hline \multirow{9}{*}{1} & Maungu & 15.5667 & 11.9377 & 0.4009 & 0.4739 \\
\hline & Titanium & 21.3140 & 15.0740 & 0.3917 & 0.4231 \\
\hline & Manyani & 14.6685 & 11.3866 & 0.3983 & 0.4720 \\
\hline & Vipingo & 19.7723 & 14.8405 & 0.4185 & 0.4905 \\
\hline & MSA cement & 33.5694 & 29.5246 & 0.4975 & 0.4941 \\
\hline & Kilifi & 49.5824 & 40.1924 & 0.5895 & 0.5768 \\
\hline & Jomvu & 29.9220 & 18.6153 & 0.4373 & 0.4312 \\
\hline & Voi & 30.0702 & 23.5100 & 0.4789 & 0.5186 \\
\hline & New Maungu & 40.7907 & 26.6191 & 0.5283 & 0.5438 \\
\hline \multirow{6}{*}{2} & Ndhiwa & 19.8211 & 19.8089 & 0.4698 & 0.5143 \\
\hline & Awendo & 26.6542 & 28.4606 & 0.4856 & 0.5379 \\
\hline & Kisii & 29.4866 & 24.9027 & 0.4610 & 0.5065 \\
\hline & Chemosit1 & 19.4962 & 12.1343 & 0.4001 & 0.4369 \\
\hline & Chemosit2 & 17.0142 & 9.0983 & 0.3451 & 0.3726 \\
\hline & Bomet & 24.0760 & 23.5806 & 0.4755 & 0.5201 \\
\hline \multirow{6}{*}{3} & Sultan Hamud & 15.6929 & 11.3209 & 0.3854 & 0.4734 \\
\hline & Mtito Andei & 14.0628 & 10.8854 & 0.3913 & 0.4684 \\
\hline & Wote & 30.5332 & 28.0553 & 0.5121 & 0.5459 \\
\hline & Ulu & 17.3522 & 13.2633 & 0.4145 & 0.4842 \\
\hline & New Sultan Hamud & 36.8682 & 34.2071 & 0.5605 & 0.5858 \\
\hline & Kiboko & 37.9508 & 31.3107 & 0.5515 & 0.5660 \\
\hline \multirow{2}{*}{4} & Lokichar & 10.2977 & 8.6689 & 0.4098 & 0.4564 \\
\hline & Kalemngorok & 14.0835 & 12.4828 & 0.4432 & 0.5188 \\
\hline \multirow{2}{*}{5} & Garissa & 18.1251 & 17.8271 & 0.5232 & 0.5556 \\
\hline & Mwingi & 27.9716 & 24.0012 & 0.5218 & 0.5713 \\
\hline
\end{tabular}

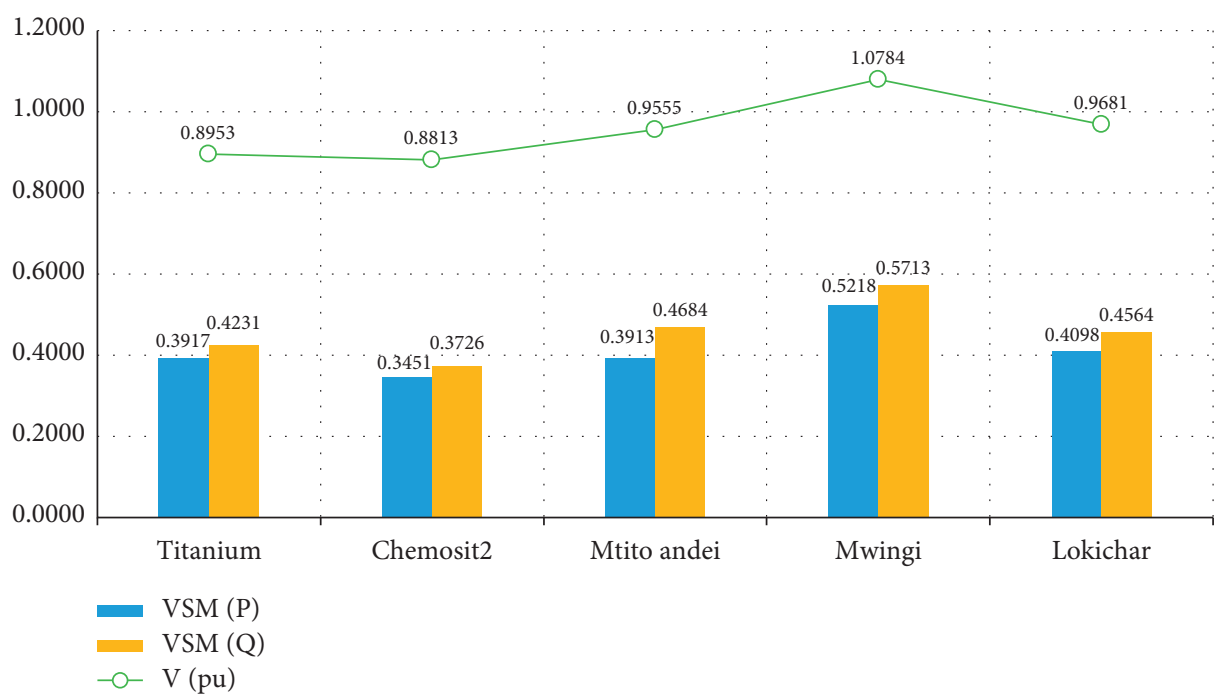

Figure 8: Comparison of bus voltages and voltage stability margins.

the outage of one of the Nairobi North to Dandora lines. Maungu and Sultan Hamud identified in Q-Modes 1 and 3, respectively, have the greatest percentage decrease in active power-voltage stability margins. In terms of reactive power, Jomvu and Maungu in Q-Mode 1 and Mtito Andei in Q-Mode 3 have the greatest decrease in voltage stability margins. A recalculation of the system eigenvalues identifies the magnitude of the smallest eigenvalue, $\left(\lambda^{-1}\right)$ as 0.12195 , an increase from 0.11958 . This coupled with the decreased voltage stability margins in the studied load buses indicates the system moves even closer to voltage instability. This is attributed to the fact that, with removal of the line, the effective power transferred decreases in the network. 
TABLE 8: Voltage stability margins of the selected load buses in critical Q-Modes after removal of the line.

\begin{tabular}{|c|c|c|c|c|c|}
\hline Q-mode & BUS & $\begin{array}{l}\text { Active power voltage } \\
\text { stability margin }\end{array}$ & $\begin{array}{c}\text { Percentage decrease in } \\
\text { VSM }(P)\end{array}$ & $\begin{array}{l}\text { Active power voltage } \\
\text { stability margin }\end{array}$ & $\begin{array}{c}\text { Percentage decrease in } \\
\text { VSM }(Q)\end{array}$ \\
\hline \multirow{9}{*}{1} & Maungu & 0.3909 & 2.4957 & 0.4690 & 1.0448 \\
\hline & Titanium & 0.3872 & 1.1539 & 0.4178 & 1.2521 \\
\hline & Manyani & 0.3928 & 1.3767 & 0.4671 & 1.0422 \\
\hline & Vipingo & 0.4102 & 1.9810 & 0.4855 & 1.0282 \\
\hline & MSA cement & 0.4923 & 1.0468 & 0.4889 & 1.0548 \\
\hline & Kilifi & 0.5807 & 1.4891 & 0.5716 & 0.8878 \\
\hline & Jomvu & 0.4313 & 1.3836 & 0.4257 & 1.2681 \\
\hline & Voi & 0.4752 & 0.7772 & 0.5137 & 0.9416 \\
\hline & New Maungu & 0.5239 & 0.8351 & 0.5389 & 0.9003 \\
\hline \multirow{6}{*}{2} & Ndhiwa & 0.4690 & 0.1678 & 0.5134 & 0.1712 \\
\hline & Awendo & 0.4833 & 0.4755 & 0.5370 & 0.1626 \\
\hline & Kisii & 0.4607 & 0.0692 & 0.5062 & 0.0578 \\
\hline & Chemosit1 & 0.3967 & 0.8679 & 0.4359 & 0.2398 \\
\hline & Chemosit2 & 0.3435 & 0.4433 & 0.3716 & 0.2578 \\
\hline & Bomet & 0.4717 & 0.7980 & 0.5190 & 0.2084 \\
\hline \multirow{6}{*}{3} & Sultan Hamud & 0.3808 & 1.1834 & 0.4688 & 0.9786 \\
\hline & Mtito Andei & 0.3865 & 1.2235 & 0.4635 & 1.0400 \\
\hline & Wote & 0.5104 & 0.3420 & 0.5408 & 0.9347 \\
\hline & Ulu & 0.4110 & 0.8428 & 0.4797 & 0.9300 \\
\hline & New Sultan Hamud & 0.5572 & 0.5998 & 0.5805 & 0.8938 \\
\hline & Kiboko & 0.5464 & 0.9205 & 0.5608 & 0.9140 \\
\hline \multirow{2}{*}{4} & Lokichar & 0.4095 & 0.0657 & 0.4560 & 0.0746 \\
\hline & Kalemngorok & 0.4430 & 0.0535 & 0.5186 & 0.0463 \\
\hline \multirow{2}{*}{5} & Garissa & 0.5215 & 0.3237 & 0.5539 & 0.3056 \\
\hline & Mwingi & 0.5207 & 0.2087 & 0.5694 & 0.3353 \\
\hline
\end{tabular}

\section{Conclusion}

In this paper, a methodology is proposed for carrying out static voltage stability assessment in bulk power systems. The methodology is employed in the assessment of the static voltage stability status of the Kenyan Power Network based on a model of the system as of 2019 has been carried out. QV Modal analysis, a practical based approach towards static voltage stability assessment of bulk power systems, has been effectively employed to determine load regions most susceptible to instability in the network. Maungu, Ndhiwa, Sultan Hamud, Lokichar, and Garissa have been identified as load buses contributing the most towards voltage instability in the various load regions identified. The bus VQ sensitivities of the system have also been determined to identify buses that have the largest reactive power changes for reactive power imports in the network. QV modal analysis and VQ sensitivity analysis complement each other as the buses having the highest participation factors in their respective Q-Modes also have the highest VQ sensitivities in the network. The critical lines in the network, based on the reactive power loss sensitivities for the Q-Modes analysed, have also be identified. These are lines that consume or supply the most reactive power for reactive power imports in the system.

Further, the load buses with the highest participation factors in the various load regions have been analysed using voltage stability margins with an aim of determining the proximity of these buses towards voltage instability. Titanium, Chemosit2, Mtito Andei, Lokichar, and Mwingi are identified as the buses closest to instability in the network, since they have the lowest voltage stability margins, with Chemosit2 having the lowest VSM values among the 5 buses. These are buses that require voltage support in the network. This study has provided a useful approach towards static voltage stability assessment of bulk power systems, especially in identifying regions most susceptible instability, the contributing factors, and in the identification of buses that are in dire need of voltage support in the system. The proposed methodology can be particularly useful especially when it comes to carrying out studies aimed at maintaining the voltage security of a system.

\section{Data Availability}

Research data used to support the findings of this study are available from the corresponding authors upon request.

\section{Conflicts of Interest}

The authors declare they have no conflicts of interest.

\section{Supplementary Materials}

Tables SI-SIII present the participation factors in Q-Modes 1-3. (Supplementary Materials) 


\section{References}

[1] M. Glavic and D. Novosel, Voltage Stability Monitoring, Instability Detection and Control, Quanta Technology, Raleigh, NC, USA, 2011.

[2] V. Ajjarapu and B. Lee, "Bibliography on voltage stability," IEEE Transactions on Power Systems, vol. 13, no. 1, pp. 115$125,1998$.

[3] North American Electric Reliability Council, System Disturbances: Review of Selected 1996 Electric System Disturbances in North America, North American Electric Reliability Council, Princeton, NJ, USA, 1996.

[4] J. M. Ordacgi Filho Brazilian Blackout 2009: Blackout Watch Protection, Automation and Control World, 2010, http://www. pacw.org/fileadmin/doc/MarchIssue2010/Brazilian_ Blackout_march_2010.pdf.

[5] Y. Hain and I. Schweitzer, "Analysis of the power blackout on june 8, 1995 in the Israel electric corporation," IEEE Transactions on Power Systems, vol. 4, no. 12, pp. 1752-1758, 1997.

[6] P. Pourbiek, P. Kundur, and C. W. Taylor, "The anatomy of power grid blaclout," IEEE Power and Energy Magazine, vol. 5, no. 4, pp. 22-29, 2006.

[7] L. D. Vargas, R. D. Miranda, and V. H. Quintana, "Voltage collapse scenario in the Chilean interconnected system," IEEE Transactions on Power Systems, vol. 4, no. 14, pp. 1415-1421, 1999.

[8] C. D. Vournas, V. C. Nikolaidis, and A. A. Tassoulis, "Postmortem analysis and data validation in the wake of the 2004 athens blackout," IEEE Transactions on Power Systems, vol. 3, no. 21, pp. 1331-1339, 2006.

[9] D. M. Kosterev, C. W. Taylor, and W. A. Mittelsadt, "Model validation for the august 10, 1996 WSCC system outage," IEEE Transactions on Power Systems, vol. 14, no. 3, pp. 967979, 1996.

[10] J. G. Ndirangu, J. N. Nderu, A. M. Muhia, and C. M. Maina, "Power quality challenges and mitigation meaures in grid integration of wind energy conversion system," in Proceedings of the IEEE International Energy Conference (ENERGYCON), Limassol, Cyprus, June 2018.

[11] T. V. Custem and C. Vournas, Voltage Stability Analysis in Electrical Power Systems, Springer Science, New York, NY, USA, 1998.

[12] P. Kundur, Power System Stability and Control, McGraw-Hill, New York, NY, USA, 1994.

[13] IEEE Committee Report, Voltage Stability of Power Systems: Concepts, Analytical Tools and Industrial Experience, IEEE/ PES, Piscataway, NJ, USA, 1990.

[14] IEEE/CIGRE Joint Task Force on Stability Terms and Definitions, "Definition and classification of power system stability," IEEE Transactions on Power Systems, vol. 19, no. 2, pp. 1387-1401, 2004.

[15] C. W. Taylor, Power System Voltage Stability, McGraw-Hill, New York, NY, USA, 1993.

[16] B. Gao, G. K. Morison, and P. Kundur, "Volatge stability analysis using static and dynamic approaches," IEEE Transactions on Power Systems, vol. 8, no. 3, pp. 1159-1171, 1993.

[17] M. Youjie, L. Shaofeng, Z. Xuesong, and G. Zhiqiang, "Review analysis of voltage stability in power system," in Proceedings of the IEEE International Conference on Mechatronics and Automations, Takamatsu, Japan, August 2017.

[18] X. Y. Zhao, X. B. Zhang, and X. L. Su, "Voltage stability and bifurcation theory in power systems," Transactions of China Electrotechnical Society, vol. 23, pp. 87-95, 2008.
[19] A. S. Mendoza, F. Esquivel, and C. R. Becerril, "A numerical study on the effect of degenerate hopf bifurcations on the voltage stability of power systems," Electrical Power Systems Research, vol. 101, no. 8, pp. 102-109, 2013.

[20] Y. J. Ma, X. S. Li, and X. S. Zhou, "The comments on dynamic bifurcation of voltage stability in power systems," ICIE, IEEE, vol. 355 , , pp. $272-275,2010$.

[21] T. J. Overbye and C. L. Demarco, "Improved technique for power system voltage stability assesment using energy methods," IEEE Transactions on Power Systems, vol. 9, no. 1, pp. 1446-1452, 1991.

[22] T. J. Overbye, I. Dobson, and C. L. DeMarco, "Q-V curve interpretations of energy measures for voltage security," IEEE Transactions on Power Systems, vol. 9, no. 1, pp. 331-340, 1994.

[23] C. A. Canizares, I. Dobson, T. Van Cutsem et al., Voltage stability assesment: concepts, practices and tools," IEEE-PES power systems stability subcommittee special publication, 2003.

[24] V. Ajjarapu and C. Christy, "The continuation power flow: a tool for steady state voltage stability analysis," IEEE Transactions on Power Systems, vol. 8, no. 1, pp. 415-423, 1992.

[25] V. Ajjarapu, Computational Techniques for Voltage Stability Assessment and Control, Springer Science, New York, NY, USA, 2006.

[26] P.-A. Lof, G. Andersson, and D. J. Hill, "Voltage stability indices for stressed power systems," IEEE Transactions on Power Systems, vol. 8, no. 1, pp. 326-335, 1993.

[27] B. Gao, G. K. Morison, and P. Kundur, "Voltage stability evaluation using modal analysis," IEEE Transactions on Power Systems, vol. 7, no. 4, pp. 1529-1542, 1992.

[28] P. Khampariya and B. Telang, "Voltage stability analysis using modal analysis," International Journal of Scientific Research, Engineering and Technology (IJSRET), vol. 4, no. 4, pp. 408411, 2015.

[29] M. Sulaiman, A. F. Bujal, and N. R. Bujah, "Voltage instability analysis on PV and QV curves for radial-type and mesh-type electrical power networks," International Review of Electrical Engineering (IREE), vol. 10, no. 1, pp. 109-115, 2015.

[30] R. Bujal, E. A. Hassan, and M. Sulaiman, "Analysis of voltage stability in power systems," in Proceedings of the International Conference of Engineering Technology and Technoprenuership, Kuala Lumpur, Malaysia, August 2014.

[31] A. Parma and G. Radman, "A new approach for estimating voltage collapse point based on quadratic approximation of PV curves," Electric Power Systems Research, vol. 79, pp. 653-659, 2009.

[32] F. O. Enemuoh, J. C. Onuegbu, and E. A. Anazia, "Modal based analysis and evaluation of voltage stability of bulk power systems," International Journal of Engineering Research and Development, vol. 6, no. 12, pp. 71-79, 2013.

[33] B. Maya and R. Sunitha, "Voltage stability assessment of large power systems using modal analysis," in Proceedings of the International Conference on Emerging Trends and Electrical Computer Technology, Nagercoil, Tamilnadu, India, March 2011.

[34] C. Mitali and S. Patra, "Voltage stability analysis using conventional methods," in Proceedings of the International Conference on Signal Processing, Communication, Power and Embedded Systems (SCOPES), Odisha, India, October 2016.

[35] R. Toma and M. Gavrilas, "Volatge stability assessment based on load flow sensitivity method," in Proceedings of the International Conference and Exposition on Electrical and Power Engineering, Romania, Balkans, October 2018. 
[36] M. M. A. Seedahmed, S. A. K. Mokred, and G. Kamara, "Voltage stability estimation for complex power system based on modal analysis technique," in Proceedings of the 6th International Conference on Signal Processing and Intergrated Networks, Noida, India, March 2019.

[37] J. Patino, C. A. Ramires, and J. Espinoza, "Modal analysis for power system benchmark with topographical changes," Communications in Computer and Information Science, vol. 1052, 2019.

[38] W.-X. Mao, Q. Yang, M.-Y. Yang, S. Zhang, F. Gao, and Y.-T. Song, "Static voltage stability analysis of power system using the combination of PV curve and modal analysis," in Proceedings of the International Power, Electronics and Materials Engineering Conference, Dalian, China, May 2015.

[39] Y. A. Jabri, N. Houseinzadeh, R. A. Abri, and A. A. Hinai, "Voltage stability assessement of a microgrid," in Proceedings of the IEEE 8th GCC Conference and Exhibition, Muscat, Oman, February 2015.

[40] B. Ombuki and R. Orenge, "Steady-state voltage stability assessment of the Kenyan high voltage transmission network," in Proceedings of the 2019 IEEE AFRICON, Accra, Ghana, September 2019.

[41] B. Sourav, G. Chandramouli, and C. Surmana, "Voltage stability margin and maximum loading point of a multi-bus system before and after compensation," International Journal of Engineering Research and Development, vol. 5, no. 7, pp. 30-35, 2013.

[42] F. Mahmood, S. Ahmad, G. Mukita, S. Razwan, M. Maruf, and F. Abatsh, "Weakest location exploration in IEEE-14 bus system for voltage stability improvement using STATCOM, synchronous condenser and static capcitor," in Proceedings of the IEEE Conference on Electrical, Computer and Communication, Cox's Bazar, Bangladesh, February 2017.

[43] M. K. Jalboub, H. S. Rajamani, R. A. Abdi-Alhameed, and A. M. Ihbal, "Weakest bus identification based on modal analysis and singular value decomposition techniques," in Proceedings of the 1st International Conference on Energy, Power and Control (EPC-IQ), Basrah, Iraq, December 2010.

[44] M. A. Djari, L. Benasal, and W. Rahnouni, "Voltage stability assessment using VQ sensitivity and modal analyses methods," in Proceedings of the 5th International Conference on Electrical Engineering, Boumerdes, Algeria, October 2017.

[45] J. G. Mercado, V. Reyes, H. T. Hernandz, and J. Z. Ayala, "Voltage stability assessment by modal analysis and load flow linear sensitivity techniques," in Proceedings of the IEEE International Autumn Meeting on Power Electronics and Computing, Ixtapa, Mexico, November 2018.

[46] V. Puppala and P. Chandrarao, "Analysis of continuous power flow method, model analysis, linear regression and ANN for voltage stability assessment for different loading conditions," Procedia Computer Science, vol. 47, pp. 168-178, 2015.

[47] A. B. Almeida, E. V. De Lorenci, R. C. Leme, A. C. Z. Souza, B. I. L. Lopes, and K. Lo, "Probabilistic voltage stability assessment considering renewable sources with the help of the PV and QV curves," IET Renewable Power Generation, vol. 7, no. 5, pp. 521-530, 2013.

[48] V. N. Sewdien, R. Preece, J. R. Torres, and M. Meijder, "Evaluation of PV and QV based voltage stability analyses in converter dominated power systems," in Proceedings of the IEEE PES Asia-Pacific Power Energy Engineering, Kota Kinabalu, Malaysia, October 2018.

[49] N. Manjul and M. S. Rawat, "PV/QV curve based optimal placement of statc VAR system in power network using
DigSILENT PowerFactory," in Proceedings of the IEEE 8th Power India International Conference, Kurukshetra, India, December 2018.

[50] X. Liang, X. Yan, and N. Khan, "Measurement based characteristic curves at point of interconnection of wind farms," in Proceedings of the IEEE Electrical Power and Energy Conference, Toronto, Canada, October 2018.

[51] R. Kumal, A. Mittal, N. Sharma, A. Kumal, and I. Duggal, "PV and QV curve analysis using series and shunt compensation," in Proceedings of the IEEE 9th Power India International Conference, Sonepat, India, March 2020.

[52] I. C. Guradin, Z. Muslimin, A. M. Ilyas, and A. Siswan, "Comparison of voltage stability index before and after wind turbine penetrated to sulsetrebar interconnection power system using modal analysis method," Material Science and Engineering Conference Series, vol. 875, 2020.

[53] Y. Burak, "Investigation with modal analysis of effects of high PV penetration on power system voltage stability," International Journal of Energy and Smart Grid, vol. 2, no. 1, pp. 17-26, 2017.

[54] A. Phadke, S. K. Banisal, and K. Rheman, "A comparison of voltage stability indices for placing shunt FACTs controllers," in Proceedings of the 1st International Conference on Emerging Trends in Engineering and Technology, Thrissur, Kerala, India, January 2018.

[55] M. Moghavemmi and F. Omar, "Technique for contigency monitoring and voltage collapse prediction," IEE Proceedings on Generation, Transmission and Distribution, vol. 145, pp. 634-640, 1998.

[56] P. Kessel and H. Glavitsch, "Estimating the voltage stability of a power system," IEEE Transactions on Power Delivery, vol. 1, no. 3, pp. 346-354, 1986.

[57] I. Musirin and A. Rahman, "Estimating maximum loadability for weak bus identification using FVSI," IEEE Power Engineering Review, vol. 22, no. 11, pp. 50-52, 2002.

[58] M. W. Mustafa and F. A. Althowibi, "Voltage stability calculations in power transmission lines: indication and allocations," in Proceedings of the IEEE International Conference on Power and Energy, Kuala Lumpur, Malaysia, December 2010.

[59] A. Mohammed, G. Jasmon, and S. Yusoff, "A static voltage collapse indicator using line stability factors," Journal of Industrial Technology, vol. 7, pp. 73-85, 1989.

[60] C. Reis and M. Barbosa, "A comparison of voltage stability indices," in Proceedings of the IEEE Mediteranean Electrotechnical Conference, Malaga, Spain, May 2006.

[61] E. Gholipour, J. Modarresi, and A. Khodabakhshian, "A comprehensive review of voltage stability indices," Renewable Energy and Sustainable Energy Review, vol. 63, pp. 1-12, 2016.

[62] S. S. Danish, T. Senjyu, S. S. Danish, R. N. Sabory, K. Narayan, and P. Mandal, "A recap on volatge stability indices in the past three decades," Energies, vol. 12, no. 8, 2019.

[63] H. Zaheb, M. S. S. Danish, S. Tomonobu et al., "A contemporary novel classification of voltage stability indices," Applied Sciences, vol. 10, no. 5, p. 1639, 2020.

[64] R. Omar, M. Sulaiman, A. Kadir, and A. F. Mohamad, "Determining voltage stability margin values by measuring hypotenuse under PV and QV curves," International Journal of Electrical Engineering and Applied Sciences, vol. 1, no. 1, 2018. 